\title{
Transporte Escolar no Campus de Poços de Caldas da Universidade Federal de Alfenas: Otimização de Rotas
}

\author{
César Ambrogi Ferreira do Lago \\ E-mail: cesar-lago@hotmail.com
}

\section{Luiz Felipe Ramos Turci}

E-mail: felipeturci@gmail.com

Instituto de Ciência e Tecnologia, Universidade Federal de Alfenas, campus Poços de Caldas

\begin{abstract}
RESUMO
Pode-se comparar o problema de roteamento de veículos ao Problema do Caixeiro Viajante (PCV) [3], um clássico exemplo de problema de otimização combinatória. A princípio, poderse-ia reduzi-lo a um problema de enumeração: enumeram-se todas as rotas possíveis e, calculase o comprimento para cada uma das rotas, então seleciona-se a rota de menor caminho. Este problema, contudo, é NP-Hard, portanto, não há algoritmo determinístico que o resolva em tempo polinomial $[2,4]$. Para se determinar uma rota de menor caminho então, podem-se utilizar algoritmos metaheurísticos, que não apresentam necessariamente solução ótima, mas sim a melhor solução viável resultante da sequências de iterações executadas. Um dos algoritmos metaheurístico para resolução do PCV é o da Colônia de Formigas, que é baseado no comportamento biológico das formigas, atraídas por ferormônio na procura de alimentos [1].

Neste trabalho, desenvolveu-se um algoritmo de otimização de rotas baseado no algoritmo de colonia de formigas apresentado em [1] para aplicação no roteamento de veículos de transporte que atendem aos alunos e funcionários do campus de Poços de Caldas da Universidade Federal de Alfenas. Para modelar o problema do transporte dos alunos, mapeou-se a cidade definindo vários nós (no modelo criado, cada cruzamento de ruas da cidade representa um nó), e interligações entre os nós (determinada pela existência de vias entre dois cruzamentos), definindo assim um grafo em que a distância entre dois cruzamentos interligados define a distância entre dois nós. $\mathrm{O}$ algoritmo deve, então, ser capaz de buscar a menor rota entre um nó de partida e um nó de chegada passando por um conjunto de nós obrigatórios (que são definidos como pontos de embarque/desembarque dos alunos). O algoritmo desenvolvido consiste nos seguintes passos:

1. Lê-se a matriz D de distância entre nós (para nós que não são interligados a distância é considerada infinita) e definem-se os nós obrigatórios (informado pelo usuário).

2. Aplica-se o algoritmo de colônia de formigas apresentado em [1] ao grafo definido pela matriz D obtendo-se um ciclo passando por todos os nós do grafo (assumindo-se grafo conexo). Extrai-se a ordem em que os nós obrigatórios serão visitados de acordo com a ordem em que aparecem na solução.

3. Com essa ordem, agora, constrói-se o roteamento combinando-se as melhores subrotas entre cada par desses nós obrigatórios, seguindo-se a ordem em que os mesmos devem ser visitados. Para se construir as subrotas entre cada par de nós obrigatórios, desenvolveu-se um algoritmo baseado no algoritmo de colônia de formigas para solucionar o PCV mas que não necessariamente visitasse todos os nós do grafo:
\end{abstract}


3.1. Cada par de nós obrigatórios é tratado como par (origem, destino) da subrota, de acordo com a ordem obtida anteriormente;

3.2. Aplica-se a metaheurística da colônia de formigas alterada para gerar um caminho entre os nós do par (origem, destino);

3.3. Na primeira subrota, a origem é o ponto de partida do problema, e o destino é o primeiro nó obrigatório da sequência obtida em 2. Após determinar a subrota entre o primeiro par de nós, atualizamos o valor do par, o destino da iteração anterior é considerada origem da próxima iteração, e o próximo nó obrigatório da sequência se torna o novo destino; e assim sucessivamente, até que o ultimo nó obrigatório torna-se origem e o destino seja o ponto de chegada do problema.

4. Une-se todas as subrotas previamente salvas para obter a rota final. Utilizou-se este algoritmo com 10 formigas e 100 iterações para resolver o problema teste do seguinte grafo:

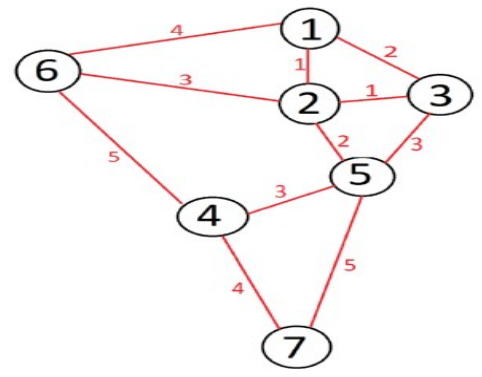

Figura 1. Grafo que define o problema teste de roteamento.

Tendo como nós obrigatórios os nós 2 e 6 , nó de partida o nó 5, e chegada o nó 7. Para este grafo, o resultado obtido foi a sequência 5,2,3,1,6,4,7 que é um bom resultado e uma das menores rotas possíveis. Para este mesmo caso, aplicando-se o algoritmo do vizinho mais próximo, por exemplo, pode não ser possível obter uma solução, pois este algoritmo sempre procura por um nó vizinho a uma menor distância e, em certo momento, chega-se a um ponto que não há mais nós vizinhos que já não tenham sido visitados. Como por exemplo seguindo sequência $1,2,3,5$, 4,7 , e a partir deste ponto, não é possível chegar em 6 sem repetir nós.

Palavras-chave: Otimização, Roteamento, Colônia de Formigas

\section{Referências:}

[1] DORIGO, M.; MANIEZZO, V.; COLORNI, A. The ant system: Optimization by a colony of cooperating agents. IEEE Transactions on Systems, Man, and Cybernetics-Part B, v. 26, n. 1, p. $1-8,1996$.

[2] GENG, X. et al. Solving the traveling salesman problem based on an adaptive simulated annealing algorithm with greedy search. APPLIED SOFT COMPUTING, v. 11, n. 4, p. 36803689, 2011.

[3] LAWLER, E. L. et al. The travelling salesman problem. New York: New York: Wiley, 1985.

[4] MAJUMDAR, J.; BHUNIA, A. K. Genetic algorithm for asymmetric traveling salesman problem with imprecise travel times. JOURNAL OF COMPUTATIONAL AND APPLIED MATHEMATICS, v. 235, n. 9, p. 3063-3078, 2011.

Apoio: FAPEMIG 